\title{
Critérios comparados de exame de Desenho Industrial: INPI, USPTO e JPO.
}

\author{
Compared criteria of Design examination: INPI, USPTO and JPO.
}

DE LA HOUSSAYE, Cássia Mota; Doutoranda em Design; Universidade do Estado do Rio de Janeiro / Escola Superior de Desenho Industrial

cassiamota@gmail.com

PERALTA, Patricia Pereira; Doutora em Artes Visuais; Universidade Federal do Rio de Janeiro / Instituto Nacional da Propriedade Industrial SOBRENOME, Nome; Titulação; Instituição de Ensino Superior

patricia.p.peralta@gmail.com

\section{Resumo}

O presente trabalho objetiva apresentar os diferentes critérios de exame empregados em três instituições de propriedade industrial para a concessão do registro de Desenho Industrial, ferramenta de proteção de propriedade industrial existente no campo da Propriedade Intelectual. As três instituições escolhidas como amostra nessa publicação são: o Instituto Nacional da Propriedade Industrial, no Brasil, o United States Patent and Trademark Office, nos Estados Unidos, e, por fim, o Japan Patent Office, no Japão. Iniciaremos com uma introdução a respeito da relação entre Propriedade Industrial e Desenho Industrial, passando então para uma evolução da proteção através de um panorama histórico. Passaremos então a um resumo dos critérios de exame para a concessão da proteção ao Desenho Industrial nos três institutos. Por fim, compararemos os critérios de exame nesses três diferentes países, apreciando as diferenças de tratamento que transparecem no escopo da proteção e também nas definições presentes nas respectivas ferramentas de proteção da propriedade industrial.

Palavras Chave: direitos de propriedade industrial; desenho industrial; critérios de exame.

\begin{abstract}
The present work aims to present the different examination criteria employed in three industrial property institutions for the granting of Industrial Design registration, an industrial property protection tool in the field of Intellectual Property. The three institutions chosen as a sample in this publication are: the National Institute of Industrial Property in Brazil, the United States Patent and Trademark Office in the United States, and, finally, the Japan Patent Office in Japan. Starting with an introduction to the relation between Intellectual Property and Industrial Design, the text will proceed to an historical panorama of the evolution of industrial protection. Then the text will lead to a comparison of the examination criteria in these three different countries, appreciating the differences in treatment that appear in the protection scope and also in the design definitions present in the respective industrial property protection tools.
\end{abstract}

Keywords: industrial property rights; design; examination criteria. 


\section{Introdução}

O desenho industrial é reconhecidamente um campo de projeto de novos objetos que visam a facilitar a nossa vida cotidiana. Hoje, a ideia de projeto vai muito além dos objetos do diaa-dia e envolve processos e formas organizacionais. O campo de produção dos designers vem sendo cada vez mais ampliado e trazendo novos desafios, constantes, àqueles que se aventuram no mesmo.

Todavia, no início do século XIX, quando se pensava o desenho industrial apenas como um ofício de projetar novos produtos, percebeu-se que essa atividade agregava valor e criava diferenciação no mercado. Assim, aquele que investia no desenho de novos objetos promovia essa diferenciação, destacando-se dos demais concorrentes e, com isso, por óbvio que seja, desejando auferir vantagens. Entretanto, como auferir alguma vantagem sem que essa atividade de projeto pudesse contar com alguma proteção?

A proteção ao fruto da atividade de desenvolvimento de novos produtos surgiu assim que foi percebida que a mesma seria estratégica para os empreendedores da época na apropriação dos lucros advindos de suas tentativas de se distinguirem de seus concorrentes pela inserção de produtos mais condizentes aos novos hábitos de consumo. Se os primeiros debates acerca da necessidade de produtos industrializados mais harmoniosos e belos aparecem após a primeira Revolução Industrial, a busca por algum tipo de proteção revela-se contemporânea a esse movimento.

Passados quase dois séculos das primeiras legislações que protegiam os desenhos industriais de algumas indústrias específicas, o campo de conhecimento sobre a proteção do desenho industrial ainda parece embrionário e resistente ao aprofundamento das categorias forjadas ao longo desse período. Isso não impede, e nem deve fazê-lo, a evidenciação do campo da proteção visando à ampliação do debate e à análise das categorias que o compõem.

Este artigo tem como objetivo, exatamente, apresentar o campo de proteção aos desenhos industriais de forma que o mesmo possa ser compreendido pelo público e expandido em pesquisas futuras. A propriedade intelectual, que abarca a proteção aos desenhos industriais, é peça chave no mundo contemporâneo, sendo utilizada estrategicamente por aqueles que querem se posicionar com vantagens em relação à concorrência. Nesse cenário, o desconhecimento tornase aliado do fracasso.

Com as discussões a serem empreendidas a seguir e os dados apresentados dos escritórios de depósitos de desenhos industriais, crê-se no atendimento da proposição deste artigo, trazendo a ideia do que seja o sistema de proteção, a harmonização que o mesmo possui internacionalmente, apesar da independência tida pelos países em formular suas legislações, bem como na oportunidade de poder se colocar tal sistema disponível para o aprofundamento e as críticas que só podem existir dentro de um ambiente de produção acadêmica.

Na busca pelo alcance do objetivo traçado, o trabalho ora apresentado utiliza metodologia exploratória. Além de embasamento bibliográfico específico sobre a proteção dos desenhos industriais, o método aqui escolhido foi delineado a partir da coleta de informações sobre os requisitos e óbices à proteção de desenhos industriais junto aos sítios e seus bancos de dados dos escritórios de propriedade intelectual do Brasil, Estados Unidos e Japão, visando à análise crítica e 
comparativa de tais resultados.

Para o atendimento ao objetivo, o artigo está dividido, além desta introdução, em mais três partes. A primeira faz uma revisão histórica de como foi forjado o campo de proteção aos desenhos industriais. Na segunda parte são apresentados os dados referentes aos requisitos e proibições legais dos países acima citados, promovendo uma análise crítica e comparativa dos mesmos. Por fim, algumas conclusões sobre o trabalho aqui desenvolvido e os desafios encontrados.

Espera-se que este artigo seja suficientemente provocante para despertar estudantes e pesquisadores para as oportunidades e desafios existentes no campo da proteção aos desenhos industriais no Brasil, campo, este, ainda tão pouco visitado, discutido e analisado.

\section{A construção e a evolução da proteção aos desenhos industriais}

Antes de adentramos em tópicos específicos sobre a proteção dos desenhos industriais, alguns apontamentos históricos sobre a evolução dessa proteção fazem-se oportunos, tendo em vista o disposto por Otero Lastres sobre a importância evidente de um estudo histórico para a melhor compreensão de uma determinada figura jurídica ${ }^{1}$. Conforme esse autor (OTERO LASTRES, 1977:49-51), a proteção jurídica aos desenhos industriais na França, com os contornos que possui hoje, nasce intimamente ligada à indústria de seda da cidade de Lyon ${ }^{2}$.

Otero Lastres ainda divide a evolução da legislação francesa, que em muito contribuiu para as legislações de outros países, em quatro etapas, revelando que a primeira proteção, na verdade, teve que se socorrer de legislações pontuais, restritas territorialmente, para, em seguida, encontrar-se regulada por legislação que abarcava a propriedade artística e literária, que visava à proteção das criações dos escritores, compositores de música, pintores e desenhistas e não exatamente daqueles que produziam novos objetos para a indústria (OTERO LASTRES, 1977).

Gama Cerqueira, por seu turno, acrescenta a relevância que tiveram as mudanças econômicas e sociais advindas da Revolução Francesa para a proteção aos desenhos industriais:

"A proteção legal dos desenhos e modelos industriais, com o caráter de que atualmente se reveste, data, sem dúvida, da época da Revolução Francesa, quando da abolição das corporações de ofícios tornou necessário substituir os antigos regulamentos corporativos por leis especiais, destinadas a proteger e garantir os direitos dos autores de criações artísticas e industriais, ameaçados pelo regime de liberdade de comércio e indústria e da livre concorrência, então instaurado (CERQUEIRA, 1982: 639)

Os privilégios garantidos pelo monarca passaram a ser odiosos e mesmo contrários ao sistema da livre iniciativa. A proteção, assim, deveria assumir novo perfil, mais condizente com um sistema de livre concorrência no qual aquele que conseguisse superar seus concorrentes de forma leal passava a merecer proteção aos bens intelectuais que o diferenciassem dos demais.

Foi em função desse novo sistema de livre iniciativa, que os produtores de tecido de Lyon,

\footnotetext{
1 "Es evidente la importancia de un estudio histórico para la mejor comprensión de uma determinada figura jurídica: en nuestro caso, los dibujos y modelos industriales." (OTERO LASTRES, 1977:49).

${ }^{2}$ Há outros autores que confirmam esse surgimento, como Cerqueira (1982) e Marchal (2009).
} 
acima mencionados, começaram a demandar a proteção diferente daquela que possuíam por conta dos privilégios do monarca. Mas essa proteção abarcava apenas os desenhos bidimensionais. No caso da proteção aos denominados modelos industriais (formas tridimensionais) sua regulamentação surge das demandas da indústria de metal fundido, conforme Otero Lastres (1977:57). Este autor demonstra a dificuldade de abrangência das legislações para dar conta dos desenhos e modelos industriais, em função de discussões ainda incipientes acerca de que objetos de proteção estava a se tratar.

Por tais proteções resultarem do atendimento muito pontual a determinadas indústrias (de tecido ou metal fundido), os produtos de outros empreendimentos industriais poderiam não encontrar abrigo nas primeiras tentativas de criar uma legislação, começando também a demandar proteção para a suas produções, o que fez com que durante todos os séculos XIX e XX continuassem as modificações legislativas acerca da matéria (OTERO LASTRES:1977).Ainda durante os Oitocentos, também conhecido como o século das grandes exposições, os desafios legislativos acerca da proteção aos desenhos só tendiam a aumentar. Autores, inventores, projetistas demandavam proteções para além dos países dos quais eram originários por não se sentirem confortáveis em expor e apresentar seus inventos e criações que passaram a ser descaradamente copiados por estrangeiros. Como resposta a essas demandas surgem, em 1883, a Convenção da União de Paris para a proteção da Propriedade Industrial (CUP) e a Convenção da União de Berna relativa à proteção das obras literárias e artísticas (CUB), em 1886.

Os produtos industriais resultantes dos projetos apresentados nas grandes exposições poderiam, de certa forma, encontrar abrigo em ambas as Convenções. Na CUP, por serem entendidos como modelos e desenhos industriais, e na CUB, por poderem ser considerados obras de artes aplicadas. A partir do contido nessas duas Convenções, os demais países do mundo foram adequando suas legislações internas para garantir algum tipo de proteção à forma do produto industrial que fosse fruto de uma concepção criativa.

Não há como não correlacionar o início ainda titubeante da proteção com a própria construção do campo de reflexão sobre o desenho industrial que passou por alguns momentos peculiares em sua trajetória, como são o movimento Arts and Craft, o estilo Art Nouveau, o Werkbund, a escola Bauhaus e a escola de Ulm. Em meio à constituição de um campo de projeto do objeto industrial, se constituía também a proteção a esse novo objeto da criação humana.

Assim afirma-se, pois as dificuldades encontradas pela França, desde o início das tentativas de legislar sobre a matéria, para dar conta da proteção aos desenhos e modelos industriais resultou, no século $X X$, em um sistema de cumulatividade de proteções. Neste, tanto as leis de direito autoral, quanto as pertinentes à propriedade industrial, poderiam ser simultaneamente utilizadas na proteção ao desenho industrial. (OTERO LASTRES, 2008)

Em outros países, como Itália, um dupla proteção, ou cumulatividade de proteções, não parecia um acerto. Por isso, em solo italiano, cabia ao criador optar por uma das proteções, abrindo, automaticamente, mão de outras. Há ainda posicionamentos de países que nem aderem ao modelo francês e nem ao modelo italiano, apostando em um sistema de cumulatividade restritiva, na qual, desde que o aspecto artístico possa ser dissociado do industrial, o desenho industrial poderia estar protegido por ambos os institutos, propriedade industrial e direito autoral. Na verdade, a coexistência desses três sistemas no cenário internacional de proteção ao longo do 
século XX apenas reflete a hibridez daquilo denominado e compreendido como desenho industrial e a dificuldade de encontrar-se uma proteção adequada ao mesmo (OTERO LASTRES, 2008).

Atualmente, no cenário internacional, a grande diretriz legislativa é o Acordo sobre Aspectos Dos Direitos de Propriedade Intelectual Relacionados ao Comércio - cujo acrônimo em português é ADPIC e em inglês TRIPS. Este acordo reuniu as matérias presentes em diversas Convenções, incluindo a de Paris e a de Berna, gerando um conjunto de normas sobre propriedade intelectual que devem ser internalizadas e aplicadas pelos Membros da Organização Mundial de Comércio (OMC). O Brasil não pode se furtar a internalizar o citado acordo e muito do que está em nossa legislação atual sobre a proteção aos desenhos industriais reflete o ADPIC.

\subsection{A construção e evolução histórica dos desenhos industriais no Brasil}

No Brasil, as primeiras formas de proteção ao fruto da atividade de projeto de produtos industriais, como ocorreu na França, encontrou guarida nas primeiras legislações de direito autoral, quando tais produtos gozassem de valor artístico. Apesar de o país ser membro da Convenção da União de Paris desde seu surgimento, em 1883, a proteção ao denominado desenho industrial só adentrou o ordenamento nacional com o Decreto 24.507, de $1934^{3}$.

Neste Decreto, a proteção ao desenho industrial foi introduzida por meio de dois institutos, como ocorria em outros países europeus: os modelos industriais e os desenhos industriais. Estes compreendiam as formas bidimensionais aplicadas a produtos industriais. Aqueles abarcavam as formas de objetos tridimensionais, seguindo um padrão internacional surgido ainda no século XIX. Para obter a proteção por meio de um dos dois institutos, o objeto teria que atender a determinados requisitos como o da novidade, o da originalidade e o da aplicação industrial.

Com o Código da Propriedade Industrial de 1945, todos os institutos de propriedade industrial foram reunidos. Assim, passaram a constar de um mesmo Código as patentes, as marcas, os desenhos e modelos industriais e os modelos de utilidade. Seguiram-se mais três Códigos no Brasil sobre a matéria datados dos anos: 1967, 1969 e 1971. Nestes Códigos mantevese a divisão de modelos industriais e desenhos industriais e a constância dos requisitos de registrabilidade. Com a entrada em vigor da Lei de Propriedade Industrial, LPI 9279/1996, tanto modelos como desenhos industriais foram unificados em um único instituto denominado desenhos industriais. Excluindo-se esta mudança de nomenclatura, pode-se afirmar que nada foi alterado referente ao escopo e aos requisitos de proteção.

Apesar da constância legislativa na proteção aos desenhos industriais no Brasil desde o Decreto de 1934, não podemos afirmar que os problemas relatados em outros países também não foram recorrentes aqui. Os desenhos industriais, no Brasil e como visto, tiveram sua primeira proteção por meio de legislação de direitos autorais, quando possuíssem caráter artístico. Mesmo com o advento de regulamentação específica, a proteção por direito autoral nunca foi claramente afastada do desenho industrial.

Na atual LPI, há definição para o desenho industrial. Em seu artigo 95, encontra-se que:

\footnotetext{
${ }^{3}$ No Brasil, a proteção de modelos industriais e desenhos industriais só foi introduzida pelo Decreto $\mathrm{n} .24 .507$, de 29/06/1934. Até então, essas criações não gozavam de proteção, salvo se dotadas de caráter acentuadamente artístico. (CERQUEIRA apud MORO, 2009, p. 208-209)
} 
"Considera-se como desenho industrial a forma plástica ornamental de um objeto ou o conjunto ornamental de linhas e cores que possa ser aplicado a um produto, proporcionando resultado visual novo e original na sua configuração externa e que possa servir de tipo de fabricação industrial" (BRASIL, 1996).

O instituto de proteção definido, conforme o artigo citado acima, atém-se à proteção da forma, separando desta toda a questão funcional. Isso ocorre desde as primeiras formas de proteção aos produtos das primeiras indústrias e, no caso do Brasil, desde o Decreto de 1934.

Todavia, sabe-se que o projeto de um novo design envolve muito mais do que a forma do mesmo. Assim, o design de um novo produto poderá gozar não apenas da proteção por meio do instituto do desenho industrial, como, também, a partir do atendimento dos requisitos de outros institutos, obter a proteção como modelo de utilidade e mesmo como uma patente de invenção para questões de funcionalidade. Não sem razões, Otero Lastres se posiciona indicando a existência de proteções concorrentes e compreendendo o desenho industrial como um dos mais complexos institutos da propriedade intelectual (OTERO LASTRES, 2008:218).

Essa complexidade própria do desenho industrial traz desafios àqueles que criam novos designs e que devem conhecer o sistema de proteção da propriedade industrial de forma a utilizar de forma eficaz as possíveis proteções que podem ser requeridas para as formas e funções. Mas essa complexidade só é intransponível ou mal utilizada na medida em que impera um grande desconhecimento acerca da mesma. Como para fins deste artigo, interessa mais a proteção por desenhos industriais, que será objeto de análise em três países diferentes, busca-se descortinar melhor o que seja tal proteção a partir do contido na legislação brasileira, para, em seguida, comparar com dados e informações de outros dois grandes países no qual há vasta quantidade de depósitos de desenhos industriais.

\section{A concessão do Registro de Desenho Industrial: Brasil, Japão e Estados Unidos.}

Antes de avançarmos neste tópico, torna-se relevante uma informação. O Brasil segue o sistema europeu denominado Civil Law. Este sistema se contrapõe ao Common Law utilizado pelos países anglo-saxões. O Common Law é um sistema bem mais resiliente quando comparado ao Civil Law. Pelo Brasil seguir o modelo europeu, em muito a legislação brasileira se espelha e reflete a europeia, o que torna oportuno o embasamento teórico e crítico a partir da literatura não só brasileira, como também europeia. Sendo assim, a comparação com países que seguem sistemas estruturais legislativos diferentes traz mais substância para análise, como ocorre neste artigo.

\subsection{1 A concessão do Registro de Desenho Industrial no Brasil: critérios de exame}

Quadro 1 - Critérios de Registrabilidade dos Desenhos Industriais no Brasil.

\begin{tabular}{llll}
\hline Artigo da LPI & Conceito & Esclarecimentos \\
\hline 95 & $\begin{array}{l}\text { Considera-se desenho } \\
\text { industrial a forma plástica } \\
\text { ornamental de um objeto ou } \\
\text { o conjunto ornamental de }\end{array}$ & $\begin{array}{l}\text { Aspecto } \\
\text { ornamental }\end{array}$ & $\begin{array}{l}\text { Refere-se às características distintivas não atreladas } \\
\text { à funcionalidade, condicionadas às variações } \\
\text { linhas e cores que possa ser } \\
\text { aplicado a umais e estéticas de um objeto, e não parte dele. }\end{array}$ \\
\hline
\end{tabular}




\begin{tabular}{|c|c|c|}
\hline $\begin{array}{l}\text { proporcionando resultado } \\
\text { visual novo e original na sua }\end{array}$ & $\begin{array}{l}\text { Configuração } \\
\text { Externa }\end{array}$ & $\begin{array}{l}\text { Relaciona-se com a visibilidade externa da forma, } \\
\text { desconsiderando componentes internos. }\end{array}$ \\
\hline $\begin{array}{l}\text { configuração externa e que } \\
\text { possa servir de tipo de }\end{array}$ & $\begin{array}{l}\text { Tipo de fabricação } \\
\text { industrial }^{4}\end{array}$ & $\begin{array}{l}\text { Refere-se à reprodutibilidade do objeto de maneira } \\
\text { homogênea com técnicas industriais. }\end{array}$ \\
\hline
\end{tabular}
fabricação industrial.

96 O desenho industrial é Novidade considerado novo quando não compreendido no estado da técnica.

Determina que nenhum Desenho Industrial idêntico ou muito semelhante possa ter sido registrado ou tornado público anteriormente à data do depósito objeto examinado ${ }^{5}$.

97 O desenho industrial é considerado original quando dele resulte uma configuração visual distintiva, em relação a outros objetos anteriores.

Originalidade Refere-se à singularidade do objeto em face de objetos anteriores, e ao passo criativo formal dado no projeto do objeto, ainda que haja combinação de elementos conhecidos ${ }^{6}$.
Não se considera desenho industrial qualquer obra de caráter puramente artístico.
Puramente artístico Fica claro nesse trecho da lei que o conceito de Desenho Industrial exclui a forma concebida unicamente como expressão pessoal do autor, aquela forma na qual o destino é a fruição estética e não o aproveitamento industrial ${ }^{7}$.
100 Não é registrável (...)

I - o que for contrário à moral

e aos bons costumes ou que ofenda a honra ou imagem de pessoas, ou atente contra liberdade de consciência, crença, culto religioso ou idéia e sentimentos dignos de respeito e veneração;

II - a forma necessária comum ou vulgar do objeto ou, ainda, aquela determinada
Contrário à ordem

Trata-se de algo q contrário aos costumes e à moral de um determinado grupo social, ofensivo ou discriminatório.

\begin{tabular}{ll}
\hline Forma necessária & $\begin{array}{l}\text { Trata-se da forma imprescindível para que aquele } \\
\text { objeto seja considerado como tal. }\end{array}$ \\
\hline Forma comum & $\begin{array}{l}\text { Considera-se comum a forma amplamente explorada } \\
\text { num campo de aplicação definido. }\end{array}$ \\
\hline Forma vulgar & $\begin{array}{l}\text { Consideram-se vulgares as formas geométricas } \\
\text { básicas, bi ou tridimensionais, derivadas dos } \\
\text { polígonos ou sólidos essenciais. }\end{array}$ \\
\hline
\end{tabular}

Considerações $\quad \mathrm{O}$ aspecto ornamental é secundário ou inexiste nas

${ }^{4} \mathrm{O}$ requisito da aplicação industrial é relacionado por Cerqueira à necessidade de ser explorado industrialmente 0 objeto cuja proteção se dê pelo desenho industrial (CERQUEIRA, 1982 :691). O mesmo afasta do campo de proteção dos desenhos industriais os trabalhos artesanais e artísticos.

${ }^{5}$ Os autores, nacionais ou estrangeiros, se posicionam a favor de uma noção objetiva de novidade (CERQUEIRA, 1984 ; MORO, 2009 ; BARBOSA ${ }^{5}$, 2003 e 2013 ; SZALEWSKI e PIERRE ${ }^{5}, 1996$; OTERO LASTRES 5 , 1977 E 1978.

${ }^{6}$ Diferentemente da novidade, SZALEWSKI e PIERRE (1996) falam da noção subjetiva de originalidade, apontando aprozimação entre a originalidade dos desenhos industriais àquela do direito autoral, no qual considera-se original algo fruto de uma criação pessoal do autor e não mera cópia. Não nos parece ser o sentido dado pelo legislador brasileiro ao requisito de originalidade, que prover o desenho de capacidade de diferenciação em relação aos objetos anteriores. Da interpretação do requisito da originalidade parece se aferir ter sido a intenção do legislador pátrio que não sejam concedidos desenhos que possuam entre si proximidades morfológicas que sejam incapazes de aumentar o que Otero Lastres (1977 e 1978) define como o " patrimônio das formas estéticas empregadas na indústria ».

${ }^{7}$ Observa-se, neste caso, que o legislador foi enfático em relação às obras de caráter puramente artístico, afastandoas da proteção por meio de desenhos industriais e apontando que, em todo o caso, no Brasil, não se optou por um sistema de cumulatividade absoluta de proteções. Para as obras de caráter puramente artístico, tem-se a proteção do direito autoral. Todavia, àquelas que conjugam caráter artístico e utilitário, permanecem as contendas acerca se poderiam ser ou não abrangidas, concomitantemente, pela proteção autoral e pela proteção aos desenhos industriais. 

funcionais.

\subsection{A concessão do registro de Industrial Design no Japão: critérios de exame}

O marco legal que regula a concessão de direitos de propriedade industrial relativos aos desenhos industriais no Japão é o Design Act, lei de 1959. No Japão as leis que regulam a propriedade intelectual são específicas e formam em conjunto um sistema de direitos que podem ser complementares: lei das patentes, lei dos modelos de utilidade, lei do design, lei dos segredos comerciais, entre outras leis.

Quadro 2 - Critérios de Registrabilidade dos Desenhos Industriais no Japão.

\begin{tabular}{|c|c|c|c|}
\hline \multicolumn{2}{|c|}{ Tradução de trechos do Design Act } & \multirow{2}{*}{$\begin{array}{l}\text { Conceito } \\
\text { Um artigo ou } \\
\text { parte dele }\end{array}$} & \multirow{2}{*}{$\begin{array}{l}\text { Esclarecimentos } \\
\text { Há o princípio da singularidade: um pedido de } \\
\text { registro para cada artigo ou parte de artigo. }\end{array}$} \\
\hline 2 & $\begin{array}{l}\text { "Design", nesse ato deve significar a } \\
\text { forma, os padrões ou cores, ou }\end{array}$ & & \\
\hline & $\begin{array}{l}\text { qualquer combinação dos mesmos, } \\
\text { de um artigo (incluído a parte de um } \\
\text { artigo) que cria uma impressão } \\
\text { estética através do olho. }\end{array}$ & $\begin{array}{l}\text { Impressão } \\
\text { estética }\end{array}$ & $\begin{array}{l}\text { Em geral é considerada a impressão visual do artigo } \\
\text { a olho nu, exceto quando for praxe no mercado o } \\
\text { uso de ampliações ou outros recursos mecânicos, } \\
\text { como no caso de gemas preciosas e jóias. }\end{array}$ \\
\hline
\end{tabular}

3 O criador de um design que seja industrialmente aplicável pode ter o direito de obter o registro para o referido design.
Aplicabilidade Refere-se à possibilidade de o mesmo artigo ser Industrial produzido em grandes volumes de maneira repetida por meio de tecnologia industrial.

3 Não são considerados novos:

(1) (i) Designs tornados públicos no Japão ou em país estrangeiro, antes do depósito do pedido de registro.

(ii) Designs descritos em uma publicação distribuída, ou designs tornados públicos por meios elétricos de telecomunicação no Japão ou no exterior antes à data do depósito do pedido de registro.

(ii) Designs similares aos descritos nos itens precedentes.
Novidade

O objeto examinado não pode fazer parte do estado da técnica, ou seja, não pode ter sido publicado em data anterior ao pedido de registro.

Leva-se em consideração o momento do depósito e a quem foi tornado público: pessoas não determinadas. A comparação para efeitos de similaridade leva em consideração a impressão estética objetiva causada no consumidor ou comerciante do produto, não a subjetividade do criador do design. São levados em conta ainda o uso e a função dos artigos para efeitos de determinação de similaridade.

3 São irregistráveis, designs onde, Dificuldade

Designs que são considerados (por pessoas

\footnotetext{
${ }^{8}$ Para a aplicação desta proibição, em países europeus, alguns critérios são apontados como o de multiplicidade das formas e o da incidência da variação da forma de um objeto sobre o resultado por este produzido (OTERO LASTRES, 2008). Quanto ao primeiro, entende-se existir dissociação entre a forma e a função quando um objeto pode adotar múltiplas formas sem deixar de produzir determinado resultado técnico. Por seu turno, em relação ao segundo, há indicação da falta de capacidade de variação da forma quando ao se variar esta se modifica o resultado técnico produzido pela mesma (OTERO LASTRES, 2008:225-226). Esses dois critérios, que poderíamos também denominar metodologias de exame, não parecem ter sido adotados em práticas de exame no Brasil, mas são consagrados pela literatura estrangeira.
} 
(2) antes da apresentação do pedido de registro de projeto, uma pessoa com habilidades ordinárias na arte do design teria sido capaz de criar facilmente esse design com base em sua forma, padrões ou cores, ou qualquer combinação dos mesmos que foi publicamente conhecida no Japão ou um país estrangeiro, não sendo a esse concedido o registro de Design.
Criativa

ordinariamente habilidosas no campo do design) como facilmente projetáveis: baseados em formas ou padrões ordinários ou amplamente conhecidos; usando técnicas ordinárias de criação; imitando objetos naturais ou imitando obras e edifícios famosos; convertidos a práticas de negócios ou, ainda, substituindo elementos de designs já registrados.

5 São irregistráveis designs que: (i) podem ferir a ordem pública ou moralidade; (ii) podem gerar confusão com outro artigo de outrem; (iii) são constituídos por forma indispensável para garantir as funções do artigo

\begin{tabular}{ll} 
Ferir a ordem & Considera-se a possibilidade de ferir a ordem pública \\
\hline Confusão & Pondera-se a capacidade de dissuadir o público \\
\hline $\begin{array}{l}\text { Forma } \\
\text { indispensável }\end{array}$ & $\begin{array}{l}\text { Exclui o design exclusivamente constituído por forma } \\
\text { indispensável à função do artigo. }\end{array}$
\end{tabular}

\subsection{A concessão da Patente de Design nos Estados Unidos: critérios de exame}

Nos Estados Unidos as leis concernentes à propriedade industrial concentram-se no Título 35 do United States Code (USC), parte II capítulo 16, e no Título 37 do Code of Federal Regulations (CFR). Para compor os conceitos principais aqui analisados, também foi levado em consideração o Manual de procedimentos para Exames de Patentes (MPEP).

Quadro 3 - Critérios de concessão para Patentes de Design nos Estados Unidos.

\begin{tabular}{|c|c|c|c|}
\hline \multicolumn{2}{|c|}{ Tradução de trechos do 35 U.S.C } & \multirow{2}{*}{$\begin{array}{l}\text { Conceito } \\
\text { Novo }\end{array}$} & \multirow{2}{*}{$\begin{array}{l}\text { Esclarecimentos } \\
\text { A novidade refere-se ao estado da técnica, e o que } \\
\text { deve ser considerado como matéria anteriormente } \\
\text { publicada, tal como descrito no item } 102 \text { do } 35 \text { U.S.C. }\end{array}$} \\
\hline 71 & $\begin{array}{l}\text { Aquele que inventar qualquer } \\
\text { design novo, original e ornamental } \\
\text { para um artigo de manufatura }\end{array}$ & & \\
\hline & $\begin{array}{l}\text { poderá obter uma patente, sujeito } \\
\text { às exigências e condições desse }\end{array}$ & Original & $\begin{array}{l}\text { Não obviedade do design frente ao estado da técnica, } \\
\text { para uma pessoa trivialmente habilidosa em design. }\end{array}$ \\
\hline & $\begin{array}{l}\text { relativas a patentes de invenções } \\
\text { serão aplicáveis a patentes de } \\
\text { design, exceto quando especificado } \\
\text { de outra maneira. }\end{array}$ & Ornamental & $\begin{array}{l}\text { Refere-se à forma e configuração, bem como qualquer } \\
\text { indício, cor ou materiais contrastantes, representação } \\
\text { gráfica, ou outra ornamentação aplicada a um artigo. }\end{array}$ \\
\hline
\end{tabular}

\section{Tradução de trechos do MPEP}

\begin{tabular}{|c|c|c|c|}
\hline 1502 & $\begin{array}{l}\text { Um design consiste nas } \\
\text { características ornamentais visuais } \\
\text { incorporadas ou aplicadas a um } \\
\text { artigo de fabricação. Uma vez que } \\
\text { um design se manifesta na } \\
\text { aparência, o assunto de um pedido } \\
\text { de patente de design pode referir- } \\
\text { se à configuração ou forma de um }\end{array}$ & $\begin{array}{l}\text { Configuraçã } \\
\text { o ou } \\
\text { superfície ou } \\
\text { ainda a } \\
\text { combinação } \\
\text { de ambos }\end{array}$ & $\begin{array}{l}\text { Nesta definição do que é considerado design pelo } \\
\text { USPTO e pela lei americana, vê-se que há tanto a } \\
\text { dualidade tri/bidimensionalidade como o critério da } \\
\text { singularidade (uma aplicação por artigo). No caso das } \\
\text { características ornamentais, a visualidade é o principal } \\
\text { parâmetro de avaliação. Na recomendação } 1542 \text { do } \\
\text { MPEP, lê-se que "é a aparência apresentada pelo } \\
\text { artigo que cria uma impressão através do olho sobre a }\end{array}$ \\
\hline
\end{tabular}


artigo, à ornamentação de superfície aplicada a um artigo ou à combinação de configuração e ornamentação de superfície. Um design para ornamentação de superfície é inseparável do artigo ao qual é aplicado e não pode existir sozinho. Deve, portanto, ser apresentado aplicado a um artigo. mente do observador". Como predomina o princípio da singularidade (um depósito por artigo), os designs são considerados distintos se tiverem formas $e$ aparências diferentes, mesmo que sejam artigos relacionados. Contudo, múltiplas formas de realização de um conceito único podem ser arquivadas em um depósito de design, desde que a sua aparência e forma sejam semelhantes. Para comparação entre a aparência visual é levado em conta o "observador comum".
1504 Uma característica ou design

.01c ornamental é definido como aquele "criado com o propósito de ornamentação" e não pode ser o resultado ou "meramente um produto" de considerações funcionais ou mecânicas.
Falta de Para ser patenteável, um design deve ser ornamentali "primariamente ornamental". Ao determinar se um dade Design é primariamente funcional, ditado por sua finalidade utilitária, ou primariamente ornamental, o objeto do depósito é visto em sua totalidade, pois é analisada a aparência geral do artigo, não o aspecto funcional ou decorativo de cada característica.

Leva-se em consideração a possibilidade do assunto do depósito de patente de design ser considerado ofensivo

ofensivo a qualquer raça, religião, impróprio

sexo, grupo étnico ou

nacionalidade

\section{Análise comparada}

Vejamos agora as sutis diferenças que aparecem nos três diferentes países em relação à enunciação dos seus institutos legais para as condições positivas e negativas de registrabilidade.

\subsection{Das condições negativas de registrabilidade}

Começando pelas impossibilidades de concessão do registro de Desenho Industrial, ou Patente de Design, cabe pontuar que, tautologicamente falando, os enunciados englobam diferentes aspectos de uma mesma questão. Vejamos:

Quadro 4 - Comparação das condições negativas de registrabilidade

\begin{tabular}{|c|c|c|c|}
\hline Questão & Brasil (INPI) - LPI & Japão (JPO)- DESIGN ACT & EUA (USPTO)- USC+MPEP \\
\hline $\begin{array}{l}\text { Não } \\
\text { Ornamental }\end{array}$ & $\begin{array}{l}100 \text { (II) Forma determinada } \\
\text { essencialmente por considerações } \\
\text { técnicas ou funcionais }\end{array}$ & $\begin{array}{l}5 \text { (iii) Forma indispensável } \\
\text { para garantir as funções }\end{array}$ & $\begin{array}{l}\text { Primariamente funcional, } \\
\text { ditado por considerações } \\
\text { funcionais ou mecânicas }\end{array}$ \\
\hline $\begin{array}{l}\text { Contra a } \\
\text { ordem }\end{array}$ & $\begin{array}{l}100 \text { (I) Contrário à moral e aos } \\
\text { bons costumes ou que ofenda a } \\
\text { honra ou imagem de pessoas, ou } \\
\text { atente contra liberdade de } \\
\text { consciência, crença, culto religioso } \\
\text { ou ideia e sentimentos dignos de } \\
\text { respeito e veneração }\end{array}$ & $\begin{array}{l}5 \text { (i) e (ii) Passível de ferir a } \\
\text { ordem pública ou a } \\
\text { moralidade, passível de } \\
\text { gerar confusão com o artigo } \\
\text { pertencente aos negócios de } \\
\text { outra pessoa }\end{array}$ & $\begin{array}{l}\text { MPEP } 1504.01 \text { (e) Assunto } \\
\text { que pode ser considerado } \\
\text { ofensivo a qualquer raça, } \\
\text { religião, sexo, grupo étnico } \\
\text { ou nacionalidade }\end{array}$ \\
\hline
\end{tabular}

No caso da questão da não ornamentalidade, vemos que as definições têm semelhanças mas, semanticamente, há nuances na precisão sobre a determinação da funcionalidade sobre a 
forma analisada: a norma japonesa requer uma objetividade maior no exame - o termo "indispensável", constante da redação legal, é um adjetivo mais restritivo à determinação de funcionalidade do objeto. Nos casos brasileiro e americano, os advérbios empregados também variam: "essencialmente" e "primariamente". Enquanto "essencialmente" dá a ideia de que o projeto foi substancialmente ou principalmente determinado por questões não ornamentais, o adverbio "primariamente" indica a ideia de ordem e/ou priorização, ou seja, nas considerações de projeto as questões não ornamentais foram priorizadas em relação às questões ornamentais. Ainda, o assunto das questões não ornamentais varia ligeiramente: no caso brasileiro, as considerações são de ordem técnica ou funcional e, no caso americano, as considerações são de ordem funcional ou mecânica. Em resumo, a enunciação do postulado brasileiro parece ignorar que as considerações técnicas podem englobar também considerações de ordem projetual, excluindo as questões do campo do design - como, por exemplo, a gestão da forma, equilíbrio compositivo, alinhamentos e proporções matemáticas - da matriz técnica.

Passemos à questão da contrariedade à moral ou ordem pública. Vemos que nos diferentes países o que é considerado um atentado contra a moral ou desrespeitoso à ordem pública varia culturalmente. O JPO é o único a considerar dentro da categoria moral o desrespeito ao negócio de outrem. Tanto o Japão como os Estados Unidos consideram a possibilidade de danos à ordem/moral pública, enquanto a norma brasileira é mais taxativa, supondo um caráter mais objetivo na identificação daquilo que é contrário, não daquilo que pode ser contrário. Também o objeto da contrariedade varia: a normatização brasileira parece englobar mais assuntos que a americana - de um lado, considera-se liberdade de consciência, costumes, honra, crença, religião, ideia e sentimentos; de outro, considera-se raça, religião, sexo, grupo étnico e nacionalidade.

\subsection{Dos requisitos obrigatórios de registrabilidade}

Agora compararemos os indícios obrigatórios de registrabilidade nas diferentes legislações e normativas, e como esses indícios são descritos.

Quadro 5 - Comparação das condições obrigatórias de registrabilidade

\begin{tabular}{|c|c|c|c|}
\hline Questão & Brasil (INPI) - LPI & Japão (JPO)- DESIGN ACT & EUA (USPTO)- USC+MPEP \\
\hline Novidade & $\begin{array}{l}\text { 96. O desenho industrial é } \\
\text { considerado novo quando } \\
\text { não compreendido no } \\
\text { estado da técnica. } \\
\S 1 \text { o o estado da técnica é } \\
\text { constituído por tudo } \\
\text { aquilo tornado acessível } \\
\text { ao público antes da data } \\
\text { de depósito do pedido, no } \\
\text { Brasil ou no exterior, por } \\
\text { uso ou qualquer outro } \\
\text { meio, ressalvado o } \\
\text { disposto no } \S 30 \text { deste } \\
\text { artigo e no art. } 99 \text {. }\end{array}$ & $\begin{array}{l}\text { 3-1. (i) Designs tornados } \\
\text { públicos no Japão ou em país } \\
\text { estrangeiro, antes do depósito } \\
\text { do pedido de registro. } \\
\text { (ii) Designs descritos em uma } \\
\text { publicação distribuída, ou } \\
\text { designs tornados públicos por } \\
\text { meios elétricos de } \\
\text { telecomunicação no Japão ou } \\
\text { no exterior antes à data do } \\
\text { depósito do pedido de } \\
\text { registro. } \\
\text { (ii) Designs similares aos } \\
\text { descritos nos itens } \\
\text { precedentes. }\end{array}$ & $\begin{array}{l}35.103 \text { USC. Aquele que } \\
\text { inventar qualquer design novo, } \\
\text { original e ornamental para um } \\
\text { artigo de manufatura poderá } \\
\text { obter uma patente, sujeito às } \\
\text { exigências e condições desse } \\
\text { título. As disposições deste } \\
\text { título relativas a patentes de } \\
\text { invenções serão aplicáveis a } \\
\text { patentes de design, exceto } \\
\text { quando especificado de outra } \\
\text { maneira. }\end{array}$ \\
\hline Originalidade, & 97. O desenho industrial é & Onde, & 1504.03 .1 \\
\hline
\end{tabular}




\section{Dificuldade Criativa ou Não obviedade \\ considerado \\ original quando dele resulte uma configuração visual distintiva, em relação a outros objetos anteriores.}

Parágrafo único. $\mathrm{O}$ resultado visual original poderá ser decorrente da combinação de elementos conhecidos. apresentação do pedido de registro de projeto, uma pessoa com habilidades ordinárias na arte do design teria sido capaz de criar facilmente o design com base em sua forma, padrões ou cores, ou qualquer combinação dos mesmos que foi publicamente conhecida no Japão ou um país estrangeiro, não será concedido registro de Design.

2(1) Design, nesse ato deve significar a forma, os padrões ou cores, ou qualquer combinação dos mesmos, de um artigo (incluído a parte de um artigo) que cria uma impressão estética através do olho. investigações factuais básicas que orientam a avaliação da obviedade (...) aplicáveis à avaliação da patenteabilidade de design: (A) Determinar o escopo e conteúdo da anterioridade; (B) Determinar as diferenças entre a invenção declarada e a técnica anterior; (C) Resolver o nível de habilidade ordinária na arte; (D) Avaliar qualquer evidência objetiva de não-obviedade (...)

MPEP 1504.03.2 Em um pedido de patente de Design, o objeto reivindicado é o projeto incorporado ou aplicado a um artigo de fabricação (ou parte dele) e não o próprio artigo. possa ser aplicado a um produto, proporcionando resultado visual novo e original na sua configuração externa e que possa servir de tipo de fabricação industrial.

Em todos os casos vistos nas tabelas acima o que se protege é o desenho, a forma de um artigo industrial, e não o artigo em si. Nos casos americano e japonês, há o princípio da singularidade - um projeto por depósito. No caso brasileiro, admite-se mais de um projeto por depósito, respeitadas as semelhanças nas variações configurativas e dentro do máximo de vinte objetos de proteção (artigo 104 da LPI). Em todas as legislações há menção expressa às duas possibilidades de objeto de proteção: superfície ornamental (ou conjunto ornamental de linhas e cores ou, ainda, desenho aplicado) e configuração aplicada (ou projeto incorporado em artigo).

Uma sutil diferença reside ainda na condição de reprodutibilidade do projeto: no caso brasileiro, considera-se que o projeto deve ser tipo de fabricação industrial (artigo 95 da LPI), ainda que não se defina em lei o que é considerado como tipo ou não. No caso japonês, fala-se em aplicabilidade industrial (artigo 3 do Design Act), referindo-se à capacidade de reprodução do mesmo artigo em grandes volumes e repetidamente via tecnologia industrial (ver item 21.1.3 do Manual do JPO de Exame em Design). Já no caso americano, fala-se em coisa passível de reprodução (MPEP 15.44).

Analisando agora os dois critérios restantes, vemos que no caso da novidade, o entendimento é compartilhado pelos três institutos, residindo tais preceitos sobre novidade, considerados por esta análise comuns, nos acordos internacionais já citados - Convenção da União de Paris (CUP) e o acordo ADPIC/TRIPS. Respeita-se portanto a delimitação do que é considerado estado da técnica, e daquilo que é excluído dele, como as publicações feitas pelo próprio autor ou depositante dentro do período de graça que antecede o depósito. A 
particularidade está no caso japonês, que descreve detalhadamente como a publicação é considerada ou desconsiderada, e inclui expressamente os meios elétricos de telecomunicação.

Passando para o segundo requisito de registrabilidade, observa-se na formulação da nomenclatura uma diferença no entendimento que cada um dos países adota: no caso brasileiro, fala-se em originalidade e distintividade; no caso japonês, em dificuldade criativa e no caso americano, em originalidade e não obviedade.

É interessante ainda observar o sujeito para o qual um determinado design é considerado como original, distintivo ou não óbvio. A norma brasileira não é taxativa quanto a esse sujeito, recaindo a análise no examinador e nas buscas feitas quando do exame de mérito ou de processos administrativos de nulidade. Apenas há a menção a respeito da distintividade visual, não sendo pacificada a questão do grau de distinção aceitável por campo de aplicação do design, segundo a classificação internacional de Locarno $^{9}$. Nas normativas americana e japonesa, leva-se em consideração o reconhecimento visual do grau de diferenciação entre os objetos comparados e também a facilidade de criação daquele determinado projeto por uma pessoa minimamente habilidosa no campo (na "arte") do design. A doutrina executiva de exames americana atribui à não obviedade de um design um peso considerável ao exame (ver MPEP 1504 V), e leva em conta ainda as ditas considerações secundárias (ver MPEP 1504.03), como o sucesso comercial e a cópia do design por outros, como fatores relevantes para a avaliação da obviedade de um solução de design.

\section{Considerações Finais}

A relevância da proteção aos desenhos industriais ainda não foi suficientemente explorada no Brasil. Há espaço para mais textos analíticos que permitam um conhecimento mais avantajado sobre um campo que, internacionalmente, possui grande valor. $\mathrm{O}$ artigo aqui proposto tentou contribuir para, não o aprofundamento, mas a disseminação de conhecimento tão alijado do campo do projeto.

Entendemos ser de extrema relevância a ampliação do debate sobre o campo de proteção aos desenhos industriais, com políticas institucionais e públicas que norteiem ações. Os escritórios de proteção à propriedade industrial, seja aqui ou alhures, representam verdadeiro tesaurus das formas estéticas aplicadas à indústria. Servem como bancos depositários de toda a evolução das formas e das técnicas. Mas explorá-lo significa conhecer os seus elementos constituintes, apreender as formas de proteção, as definições, requisitos e óbices legais.

As reflexões acerda da proteção aos desenhos industriais é essencial em um mundo no qual tudo é apropriável e venal. Conhecer os critérios existentes para a proteção aos desenhos industriais em grandes escritórios depositantes, entender suas particularidades, é capacitar nossos desiners a usarem eficientemente o sistema de proteção a favor da produção nacional.

Assim, entende-se ter, este artigo, atingido o seu objetivo de levar uma compreensão mais detalhada de como surgiu a proteção ao desenho industrial, descortinando como o sistema atual operacionaliza essa proteção e apontando as diferenças e similaridades em critérios de exame

\footnotetext{
${ }^{9}$ A classificação internacional de Locarno é o sistema de classificação internacional para desenhos industriais que é recomendado pela Organização Mundial da Propriedade Intelectual (OMPI). O acordo de Locanro data de 1968 e é constantemente atualizado, hoje estando na sua 11a edição.
} 
existentes em três grandes escritórios de proteção à propriedade industrial. Em meio as dissemelhanças, muitas são as similaridades que podem nortear estratégias mais robustas de proteção.

\section{Referências Bibliográficas}

BRASIL. Lei 9279, de 14 de maio de 1996. Regula direitos e obrigações relativos à propriedade industrial. Disponível em http://www.planalto.gov.br/ccivil_03/leis/L9279.htm, acesso em 02/03/2018.

BARBOSA, Denis Borges. Uma introdução à propriedade intelectual. Rio de Janeiro : Lumen Juris, 2003.

Da novidade nos desenhos industriais. 2013. Disponível em: http://www.denisbarbosa.addr.com/arquivos/200/propriedade/da_novidade_di.pdf

CERQUEIRA, João da Gama. Tratado da propriedade industrial. São Paulo : Revista dos Tribunais, 1982.

ESTADOS UNIDOS DA AMÉRICA. Patent Act de 1952, 35 U.S.C. §§ 1-376. Disponível em https://www.gpo.gov/fdsys/granule/USCODE-2011-title35/USCODE-2011-title35-partll-chap16sec171, acesso em 02/03/2018.

. Manual of Patent Examining Procedure (MPEP). 9o Edição: Agosto de 2017, revisada em janeiro de 2018. Disponível em https://www.uspto.gov/web/offices/pac/mpep/index.html, acesso em 02/03/2018.

JAPÃO. Design Act. Act $\mathrm{n}$ 0125, abril de 1959. Disponível em http://www.japaneselawtranslation.go.jp/law/detail/?id=44\&vm=04\&re=02, acessado em 02/03/2018.

MARCHAL, Valérie. "Brevets, marques, dessins et modèles. Évolution des protections de propriété industrielle au XIXe siècle en France". In : Documents pour I'histoire des techniques, julho de 2009. Disponível em http://journals.openedition.org/dht/392, acesso em 02/03/2018.

MORO, Maitê Cecília Fabbri. Marcas tridimensionais. São Paulo: Saraiva, 2009.

OTERO LASTRES, José Manuel. "Reflexiones sobre el diseño industrial". In.: Anuario Facultad de Derecho. Universidad de Alcalá. p. 217-235, 2008.

."Reflexiones sobre el concepto de novedad em materia de modelos industriales".

Actas de derecho industrial. Madrid: Marcial Pons, 1978.

. El modelo industrial. Madrid : Editorial Montecorvo, 1977.

PERRET, M. François. "Quelle protection juridique?" In.: La protection des dessins et modèles: vieux débats, nouveaux enjeux. La semaine juridique. Paris: Edition Entreprise, no2 du 14 janvier 1988. Disponível em: HYPERLINK "http://www.creda.ccip.fr/colloques/pdf/1987-dessinsmodeles/dessins-actes.pdf"http://www.creda.ccip.fr/colloques/pdf/1987-dessinsmodeles/dessins-actes.pdf, acesso em 02/03/2018.

SCHMIDT-SZALEWSKI, Joana e PIERRE, J.-L. Droit de La Propriété industrielle. Paris : Librarie de la 
Cour de cassation, 1996. 